\title{
ĐIỀU TRI GÃY KÍN MÂM CHÀY SCHATZKER V-VI BẰNG NẸP KHOÁ MÂM CHÀY NGOÀI VÀ SAU TRONG QUA HAI ĐƯờnG MỔ TẠI BỆNH VIỆN THỐNG NHẤT
}

\section{TÓM TẮT}

Mục tiêu: Đánh giá điều trị gãy kín mâm chày Schatżker V VI bằng nẹp vít khoá mâm chày ngoài và sau trong qua hai đường mổ tại khoa Chấn thương Chỉnh hình, Bệnh viện Thống Nhất. Phương pháp nghiên cứu: Ṅghiên cứu hồi cứu và tiến cứu mô tả trên 18 bệnh nhân có gãy kín mâm chày Schatzker V, VI được phẫu thuật kêt hợp xương bằng nẹp vít khóa tại Bệnh viên Thổng Nhất từ 01/2018 đến 01/2021. Tất cả bệnh nhân được hẹn tái khám lâm sàng và kiểm tra phim $X$ - quang sau mổ. Kết quả: Gãy kín mâm chày loại V (14 ca) và loại VI (4 ca) theo Schatzker với tỷ lệ nam/nứ là 1,25. Trong đó từ 16 đến 45 tuổi chiếm $83.3 \%$. Nhóm nghề nghiệp thường găp tai nan chủ yếu là lái xe máy, các nghề tự do và cổng nhẩn với tỷ lệ $83.3 \%$ và nguyên nhân chấn thương $61.1 \%$ là do tai nan giao thông, $27.8 \%$ tai nạn lao động. Sau mổ $100 \%$ lành xương với kết quả $88.9 \%$ tốt và rất tốt. Phục hồi giải phẫu cải thiện cấu trúc từ đó phục hồi chức năng mang lại kết quả cao hơn với $66.7 \%$ đat tốt và rất tốt. Kết luân: Kết hợp xương gãy kín mầm chày loại V - VI theo Schatzker bằng hai nep vít khoá qua hai đường mổ mang lai kết quả phục hồi tốt và rất tốt trong giải phẫu và chức năng.

Tư khóa: Gãy kín mâm chày theo Schatzker;nẹp vít khoá mâm chày qua hai đường mổ.

\section{SUMMARY \\ TREATMENT OF TIBIAL PLATEAU FRACTURES SCHATZKER TYPE V-VI USING DUAL LOCKING PLATING AT LATERAL AND POSTERIOMEDIAL TIBIAL PLATEAU VIA 2-INCISION TECHNIQUE AT THONG NHAT HOSPITAL}

Objective: To evaluate the surgical treatment results of tibial plateau closed fracture of Schatzker $\mathrm{V}$ - VIusing dual locking plating at lateral and posteriomedial tibial plateau via2-incision technique at Thong Nhat hospital. Methods: The retrospective, prospective descriptive study was conducted on 18 elder patients with closed fractures of Schatzker V VItibial plateauhad internal fixation using dual locking plate via 2-incisions at Thong Nhat hospital, from Jan 2018 to Jan 2021. All patients were followed after surgery. Results: Closed fracture of the tibial plateau Schatzker type V (14 cases) and type VI (4 cases with the ratio of male / female is 1.25 . In which, from 16 to 45 years old, accounting for $83.3 \%$. The main

${ }^{1}$ Bệnh viện Thông Nhất, Tp Hồ Chí Minh, Việt Nam Chiu trách nhiệm chính: Võ Thành Toàn

Email: vothanhtoan1990@yahoo.com

Ngày nhận bài: 6.01.2021

Ngày phản biện khoa học: 1.3.2021

Ngày duyệt bài: 10.3.2021

\author{
Nguyễn Bảo Lục ${ }^{1}$, Võ Thành Toàn ${ }^{1}$
}

groups of occupations that have accidents are mainly motorbike drivers, freelance jobs and workers with the rate of $83.3 \%$ and injury causes $61.1 \%$ due to traffic accidents, $27.8 \%$ of occupational accidents. After surgery $100 \%$ bone healing as results $88.9 \%$ good and very good. Anatomic recovery has been shown to improve good anatomical structure, from which functional rehabilitation results in higher results with $66.7 \%$ achieving good and very good results. Conclusion: The surgical treatment oftibial plateau Schatzker types V-VI closed fracture using dual locking plate via 2-incisions for good recovery anatomy and function.

Keywords: Closed fracture of tibial plateu from Schatzker classification; duallocking plate via 2-incisions.

\section{I. ĐĂT VẤN ĐỀ}

Gãy kín mâm chày là dạng gãy đầu trên xương chày thấu khớp do nhiều nguyên nhân khác nhau. Dạng gãy thường phức tạp với gãy mâm chày ngoài, mâm chày trong hoặc kết hợp cả hai. Thường gãy lún hoặc gãy toác thành nhiều mảnh kèm tổn thương phối hợp với rách sụn chêm, đứt dây chằng chéo...Có nhiều phân loại cho gãy mâm chày, nhưng phân loại Schatzker thường được áp dụng trên lâm sàng. Trong đó gãy kín mâm chày Schatzker V, VI thường khó điều trị, nguy cơ di chứng nặng nề. Vì thế phẫu thuật viên luôn lựa chọn phương pháp tối ưu phục hồi mặt khớp, giữ đúng trục cơ học, bảo toàn hệ thống gấp duỗi và giữ vững khớp gối [2].

Với phát triển y học ngày nay, phẫu thuật nẹp vít được sử dụng phổ biến trong các trường hợp gãy kín mâm chày Schatzker V-VI. Y văn cũng có nhiều phương pháp sử dụng nẹp vít như dụng một nẹp qua một đường mổ, hai nẹp qua một đường mổ, hai nẹp qua hai đường mổ. Đánh giá trên mức độ tổn thương phần mềm và khả năng cố định các mảnh gãyđể làm sao vừa cố định tốt các mảnh gãy nhưng tổn thương phần mềm tối thiểu[1]. Do đó chúng tôi nghiên cứu đề tài này nhằm: Đánh giá điều trị gãy kín mâm chày Schatzker V-VI bằng nẹp vít khoá mâm chày ngoài và sau trong qua hai đường mổ tại khoa Chấn thương Chinh hinh, Bệnh viện Thống Nhất.

II. ĐỐI TƯợNG VÀ PHƯƠNG PHÁP NGHIÊN CỨU

Đối tượng: bệnh nhân từ 16 tuổi trở lên có gãy kín mẩm chày phân loại V-VI theo Schatzker 
được điều trị tại Bệnh viện Thống Nhất từ tháng 1 năm 2018 đển tháng 1 năm 2021.

* Tiêu chuẩn chọn bệnh: bệnh nhân từ16 tuổi trở lên có gãy kín mâm chày được phân loại V-VI theo Schatzker trên $X$ - quang, bệnh nhân đồng ý tham gia nghiên cứu.

Chỉ định phẫu thuật đối với gãy mâm chày Ioại V-VI theo Schatzker [5]:

- Loại V: Gãy cả hai mâm chày có thể được cố định bằng nẹp nâng đõ̃ và vít xốp hoặc nẹp. Bên mâm chày di lệch nhiều và nát hơn được cố định bằng nẹp nâng đỡ. Mâm chày còn lại được cố định bằng vít xốp hoặc cố định bằng một nẹp chống trượt nhỏ để giảm thiểu tổn thương mô mềm.

- Loại VI: Phải mổ mở với hai đường măăt trong và mặt ngoài khớp gối để nắn chỉnh và kết xương bằng hai nẹp nâng đỡ ở mặt trong và mặt ngoài.

* Tiêu chuâin loại trừ: bệnh nhân không đồng ý tham gia nghiên cứu, hồ sơ không đủ $X$ quang trước và sau mổ, gãy hở mâm chày, gãy xương chày bệnh lý, gãy mâm chày có tổn thương kết hợp như: tổn thương mạch máu thần kinh, gãy mâm chày, gãy đâu dưới xương đùi trên cùng chi tổn thương.

Phương pháp nghiên cứu: Hồi cứu và tiến cứu mô tả, xem lại hồ sơ 18 trường hợp bệnh nhân từ 16 tuổi có gãy kín mâm chày phân loại V-VI theo Schatzker được điêuu trị tại Bệnh viện Thống Nhất từ tháng 1 năm 2018 đến tháng 1 năm 2021. Gửi thư mời bệnh nhân tái khám đối với các bệnh nhân ở tỉnh; gửi thư mời hoặc đến khám tại nhà đối với bệnh nhân ở TP.HCM. Lấy thông tin bệnh nhân: tuổi, giới tính, nghề nghiệp, cơ chế chấn thương.

Bệnh nhân tái khám được chụp $X$ - quang khớp gối thẳng nghiêng, đo tầm vận động khớp gối, đo sức cơ chi dưới. Với bệnh nhân chuẩn bị mổ được khai thác bệnh sứ, khám lâm sàng, chụp $X$ - quang thẳng - nghiêng, chụp MRI xác định tổn thương mô mềm, chụp CT - scan dựng hình khớp gối (nếu cần); Tiến hành phẫu thuật kết hợp xương mâm chày ngoài và mâm chày sau trong theo hai đường mổ, ghép xương tự thân hoặc ghép xương đồng loại, đánh giá tổn thương phần mềm.

Đánh giá liền xương đánh giá trên lâm sàng và $X$ - quang dựa theo hình ảnhcác bè xương bắc cầu qua đoạn gãy, không thãy khe gãy, hay khe gãy hẹp lại dần, mờ dần và mất đi. Kết quả gầnsau mổ được đánh giá trong 3 tháng đầudựa vào diễn biến của vết mổ và kếtquả chỉnh trục xương sau mổ kết xương vị trí của nẹp, vít so với mặt khớp mâm chày, biên độ vận động của khớp gối, các biến chứng sớm sau mổ cũng như khả năng phục hồi theo thang điểm của Hội khớp gối Hoa Kỳ [4] và phân ra 4 loại:

- Rất tốt: 90 - 100 điểm

- Tốt: 80 - 89 điểm

- Trung bình: 70 - 89 điểm

- Kém: dưới 70 điểm

Đánh giá phục hồi giải phẫu dựa theo tiêu chuẩn của Honkonen - Jarvinen [3] (Bảng 2.1) đánh giá trên $\mathrm{X}$ - quang gồm các dấu hiệu: độ nghiêng mâm chày, độ khác biệt góc chày đùi so với chân lành, độ lún mặt khớp, độ tăng bề rộng mâm chày và thoái hoá khớp.

Bảng 2.1. Tiêu chuẩn đánh giá kêt quả trên $X$-Quang theo Honkonen - Jarvinen

\begin{tabular}{|c|c|c|c|c|}
\hline Chì số X - quang & Rất tốt & Tốt & Trung bình & Kém \\
\hline Độ nghiêng mâm chày & $0^{0}$ & $1^{0}-5^{0}$ & $6^{0}-10^{0}$ & $>10^{0}$ \\
\hline Độ khác biệt góc chày đùi & $0^{0}$ & $1^{0}-5^{0}$ & $6^{0}-10^{0}$ & $>10^{0}$ \\
\hline Độ lún mặt khớp & $0 \mathrm{~mm}$ & $1-3 \mathrm{~mm}$ & $4-6 \mathrm{~mm}$ & $>6 \mathrm{~mm}$ \\
\hline Độ tăng bề rộng mâm chày & $0 \mathrm{~mm}$ & $1-5 \mathrm{~mm}$ & $6-10 \mathrm{~mm}$ & $>10 \mathrm{~mm}$ \\
\hline Thoái hoá khớp (hẹp khe khớp) & Không & $<50 \%$ & $<50 \%$ & Xoá khe khớp \\
\hline
\end{tabular}

III. KẾT QUẢ NGHIÊN CỨU

\section{1.Đặc điểm lâm sàng:}

Bảng 3.1.Phân loại gãy kín mâm chày Schatzker theo giới tính $(n=18)$

\begin{tabular}{|c|c|c|c|}
\hline \multirow{2}{*}{ Loại gãy } & \multicolumn{2}{|c|}{ Giới tính } & \multirow{2}{*}{$\begin{array}{c}\text { Tỷ lệ } \\
\text { (\%) }\end{array}$} \\
\hline V & Nam & Nữ & \\
\hline VI & 8 & 6 & 77.8 \\
\hline Tỷ lệ (\%) & 2 & 2 & 22.2 \\
\hline
\end{tabular}

Nhóm nghiên cứu ghi nhận, trong 18 bệnh nhân gãy kín mâm chày loại $\mathrm{V}$ (14 ca) và loại VI
(4 ca) theo Schatzker từ 16 tuổi trở lên thì tỷ lệ nam/nữ là 1,25 . Loại gãy gặp chủ yếu là loại $V$ theo Schatzker với tỉ lệ $77.8 \%$.

Bảng 3.2. Phân loại gãy kín mâm chày Schatzker theo tuổi ( $n=18$ )

\begin{tabular}{|c|c|c|c|c|c|}
\hline $\begin{array}{c}\text { Loại } \\
\text { gãy }\end{array}$ & \multicolumn{4}{|c|}{ Tuối } & \multirow{2}{*}{ Tổng } \\
\hline V & 6 & 5 & 2 & 1 & 14 \\
\hline VI & 3 & 1 & 0 & 0 & 4 \\
\hline $\begin{array}{c}\text { Tỷ lề } \\
\text { (\%) }\end{array}$ & 50.0 & 33.3 & 11.1 & 5.6 & 100.0 \\
\hline
\end{tabular}


Đa phần độ tuổi lao động di chuyển nhiều nguy cơ gặp tai nạn cao hơn hẳn các nhóm khác. Từ 16 đến 45 tuổi chiếm $83.3 \%$. Nhóm nghiên cứu ghi nhận có 1 ca trên 60 tuổi gãy mâm chày loại $V$, bệnh nhân thoái hoá khớp độ mức độ nhẹ trên chẩn còn lại. Các nhóm tuổi lớn hơn nguy cơ gặp tai nạn do di chuyển giảm nhưng lại có tình trạng loãng xương kèm theo.

Bảng 3.3. Phân bố bệnh nhân theo nghề nghiệp $(n=18)$

\begin{tabular}{|c|c|c|}
\hline Nghề nghiệp & Số BN & $\begin{array}{c}\text { Tỷ lệ } \\
\mathbf{( \% )}\end{array}$ \\
\hline Cán bộ, viên chức & 2 & 11.1 \\
\hline Công nhân & 5 & 27.8 \\
\hline Lái xe, tự do & 10 & 55.5 \\
\hline Hưu trí & 1 & 5.6 \\
\hline Tống & 18 & 100.0 \\
\hline
\end{tabular}

Nghề nghiệp thường gặp tai nạn chủ yếu tài xế lái xe máy, các nghề tự do và công nhân với tỷ lệ $83.3 \%$ (đa phần phải di chuyển, hoặc làm việc trên cao như giàn giáo, nhà cao tầng). Ghi nhận một trường hợp trên 60 tuổi có loãng xương bị gãy xương do tai nạn sinh hoạt, năng lượng thấp.

Thực tế hiện nay, tình trạng lái xe gắn máy tăng nhiều như tài xế công nghệ giao hàng, vận chuyển hành khách dẫn đến tî lệ tai nạn giao thông tăng cao (Bảng 3.4).

Bảng 3.4. Phânloại gãy kín mâm chày Schatzker theo nguyên nhân $(n=18)$

\begin{tabular}{|c|c|c|c|c|}
\hline \multirow{2}{*}{ Loại gãy } & \multicolumn{3}{|c|}{ Nguyên nhân } & \multirow{2}{*}{ Tổng } \\
\cline { 2 - 5 } & TNGT & TNSH & TNLĐ & \\
\hline V & 8 & 2 & 4 & 14 \\
\hline VI & 3 & 0 & 1 & 4 \\
\hline Tỷ lệ (\%) & 61.1 & 11.1 & 27.8 & 100.0 \\
\hline
\end{tabular}

Nguyên nhân gây chấn thương nhóm chúng tôi thống kê được với $61.1 \%$ là do tai nạn giao thông, kế tiếp là tai nạn lao động $(27.8 \%)$, tai nạn sinh hoạt $(11,1 \%)$. Điều này cũng phù hợp với nghiên cứu của các tác giả Hoàng Khắc Xuẩn [1], Đặng Trung Kiên [2] với tình trạng giao thông trong nước và nhu câuu lao động hiện nay.

\subsection{Kết quả sau phẫu thuât:}

Bảng 3.5. Kết quả Xquang sau mố $(n=18)$

\begin{tabular}{|c|c|c|}
\hline Kết quả & Số bệnh nhân & Tỉ lệ (\%) \\
\hline Rất tốt & 7 & 38.9 \\
\hline Tốt & 9 & 50.0 \\
\hline Khá & 2 & 11.1 \\
\hline Tống & $\mathbf{1 8}$ & $\mathbf{1 0 0 . 0}$ \\
\hline
\end{tabular}

Kết quả Xquang sau mố của chúng tôi theo bảng đánh giá của Hiệp hội khớp gối Hoa Kỳ với kết quả tốt và rất tốt đạt $88.9 \%$,khá có 2 bệnh nhân chiếm tỷ lệ $11.1 \%$. Bên cạnh đó nhóm nghiên cứu tiếp tục đánh giá kết quả lành xương trên bệnh nhân.

Bảng 3.6. Kết quả lành xương $(n=18)$

\begin{tabular}{|c|c|c|}
\hline Kết quả & Số bệnh nhân & Tỉ lệ (\%) \\
\hline Lành xương & 18 & 100.0 \\
\hline Không lành xương & 0 & 0 \\
\hline Tống & $\mathbf{1 8}$ & $\mathbf{1 0 0 . 0}$ \\
\hline
\end{tabular}

Chúng tôi đánh giá kết quả lành xương dựa vào phim $X$ - quang: các bè xương bắc cầu qua đoạn gãy, không thấy khe gãy, hay khe gãy hẹp lại dần, mờ dần và mất đi là dấu hiệu nhận biết quá trình lành xương hình thành. Xương vùng gãy có mật độ tương tự với các xương lân cận. Tất cả các ca nghiên cứu đều lành xương chiếm tỷ lệ $100 \%$.

Bảng 3.7. Đánh giá phục hồi giải phẫu dựa theo tiêu chuẩn của Honkonen - Jarvinen trên $X$-quang $(n=18)$

\begin{tabular}{|c|c|c|c|c|}
\hline $\begin{array}{c}\text { Chí số X - } \\
\text { quang }\end{array}$ & $\begin{array}{c}\text { Rất } \\
\text { tốt }\end{array}$ & Tốt & $\begin{array}{c}\text { Trung } \\
\text { bình }\end{array}$ & Kém \\
\hline $\begin{array}{c}\text { Độ nghiêng mâm } \\
\text { chày }\end{array}$ & 2 & 15 & 1 & 0 \\
\hline $\begin{array}{c}\text { Độ khác biệt góc } \\
\text { chày đưi }\end{array}$ & 14 & 3 & 1 & 0 \\
\hline Độ lún mặt khớp & 8 & 5 & 3 & 2 \\
\hline $\begin{array}{c}\text { Độ tăng bề rộng } \\
\text { mâm chày }\end{array}$ & 0 & 2 & 10 & 6 \\
\hline $\begin{array}{c}\text { Thoái hoá khớp } \\
\text { (hẹp khe khớp) }\end{array}$ & 5 & 10 & 2 & 1 \\
\hline
\end{tabular}

Bảng 3.8.Đánh giá kết quả phục hồi theo thang điểm của Hiệp hội khớp gối Hoa Kỳ ( $n=$ 18)

\begin{tabular}{|c|c|c|}
\hline Kết quả & Số bệnh nhân & Tỉ lệ (\%) \\
\hline Rất tốt & 2 & 11.1 \\
\hline Tốt & 10 & 55.6 \\
\hline Khá & 6 & 33.3 \\
\hline Tống & $\mathbf{1 8}$ & $\mathbf{1 0 0 . 0}$ \\
\hline
\end{tabular}

Đánh giá phục hồi giải phẫu dựa theo tiêu chuẩn của Honkonen - Jarvinen (Bảng 3.7) cho thấy việc phục hồi độ nghiêng mâm chày, độ lún mặt khớp đa phần và góc chày đùi nhìn nhận từ tốt và rất tốt. Độ tăng bề rộng mâm chày ở mức trung bình. Thoái hoá khớp ghi nhận hẹp mức độ trung bình. Đánh giá kết quả phục hồi chức năng theo thang điểm của Hiệp hội khớp gối Hoa Kỳ ghi nhận kết quả tốt và rất tốt đạt $66.7 \%$, khá có 6 bệnh nhân chiếm tỷ lệ 33.3\%. Trong 18 trường hợp nhóm đánh giá 4 ca gãy mâm chày loại VI theo Schatzker khả năng phục hồi chỉ đạt khá gồm có 1 trường hợp loại $\mathrm{V}$ bệnh nhân có thoái hoá khớp từ trướcvà một trường hợp loại $\mathrm{V}$ có biến chứng thoái hoá khớp gối sau tai nạn, 4 trường hợp loại VI gãy phức tạp hơn, phục hồi 
khớp gối không cao. Nghiên cứu chúng tôi có khác biệt khá lớn so với các tác giả hiện nay vì cõ mẫu không lớn, tiêu chuẩn nhận bệnh khắt khe hơn.

3.3. Đánh giá các biến chứng: Chúng tôi ghi nhận có 1 trường hợp biến chứng (16.7\%): 1 trường hợp can xấu, hẹp khe khớp nhiều và cứng khớp gối, không ca nào nhiễm trùng hoặc có biến chứng về thần kinh, mạch máu, không ca nào bắn vít vào khớp.

\section{KẾT LUÂ̂N}

Gãy kín mâm chày loại $\mathrm{V}$ - VI theo Schatzker gặp nhiều ở nam giới, trong độ tuổi lao động thường gặp tai nạn giao thông cũng như cồng việc đi lại nhiều hay ở trên cao. Việc sử dụng hai nẹp vít khóa kết hợp xương gãy kín mâm chày loại V - VI theo Schatzkermang lại kết quả phục hồi giải phẫu tốt và rất tốt. Chức năng khớp gối ổn định hơn với $66.7 \%$ phục hồi đạt tốt và rất tốt.

\section{TÀI LIÊU THAM KHẢO}

1. Hoàng Khắc Xuân (2020), "Điều trị gãy kín mâm chày Schatzker V, VI bằng nẹp khoá mâm chày ngoài và sau trong qua hai đường mổ" Luận văn bác sĩ chuyên khoa II. Trường đại học Y khoa Pham Ngoc Thach.

2. Đăng Trung Kiên (2015), "Đánh giá kết quả điều trị gã̃y kín mâm chày theo phân loại Schatzker VVi bằng nẹp khoá tại Bệnh viện Việt Đức", Luận văn bác sĩ nội trú, Đại hoc Y Hà Nội.

3. Honkonen S.E., Jarvinen M.J. (1992), "Classification of fractures of the tibial condyles".j Bone Joints Surg Br, 74B(6), 840-847.

4. Insall J.N., Dorr L.D., Scott W.N. (1989), "Rationale of The Knee Society climcal rating system". Clin Orthop, 248, 13-14.

5. Schatzker J. (1992). "Tibia plateau fractures". Skeletal Trauma. Vol.2, pp 1745-1770.

\title{
ĐốI CHIẾU HÌNH ẢNH SIÊU ÂM TỬ CUNG VớI KẾT QUẢ Mô BỆNH HỌC Ở BỆNH NHÂN ĐẾN KHÁM TẠI BỆNH VIỆN ĐẠI HỌC Y THÁI BİNH
}

\author{
Nguyễn Ngọc Trung*, Nguyễn Trung Kiên*, Phí Trọng Hiếu*
}

\section{TÓM TẮT}

Mục tiêu: Đối chiếu hình ảnh siêu âm buồng tử cung với kết quả mô bệnh học. Đối tượng và phương pháp nghiên cứu: Nghiên cứu mổ tả cắt ngang, trên 73 bệnh nhân. Kết quả: Chẩn đoán quá sản niêm mạc tử cung độ nhạy của siêu âm là $13 \%$; độ đặc hiệu là $100 \%$; giá trị chẩn đoán dương tính là $100 \%$ và giá trị chẩn đoán âm tính là $70 \%$. Chẩn đoán polype buồng tử cung độ nhạy trên siêu âm là $81 \%$; độ đặc hiệu là $70 \%$; giá trị chẩn đoán dương tính là $43 \%$ và giá trị chẩn đoán âm tính là $93 \%$. Chẩn đoán u xơ tử cung độ nhạy của siêu âm là $67 \%$; đô đặc hiệu là 94\%; giá trị chẩn đoán dương tính là $60 \%$ và giá trị chẩn đoán âm tính là $95 \%$.

Tư khoá: Buồng tử cung, mô bệnh học, siêu âm

\section{SUMMARY}

CONTRAST IMAGES OF UTERINE

ULTRASOUND WITH HISTOPATHOLOGICAL RESULTS OF PATIENTS EXAMINED AT THAI

BINH MEDICAL UNIVERSITY HOSPITAL

Objectives: To compare ultrasound images of the uterus with histopathological results. Subjects and research methods: A cross-sectional descriptive study, on 73 patients. Results: Diagnosis of

*Đại học Y Dược Thái Binh

Chịu trách nhiệm chính: Nguyễn Ngọc Trung

Email: trungnn@tbump.edu.vn

Ngày nhận bài: 2.01.2021

Ngày phản biện khoa học: 1.3.2021

Ngày duyệt bài: 10.3.2021 endometrial hyperplasia the sensitivity of ultrasound is $13 \%$; specificity is $100 \%$; The positive diagnostic value is $100 \%$ and the negative diagnostic value is $70 \%$. Diagnosis of uterine polype sensitivity on ultrasound is $81 \%$; specificity is $70 \%$; The positive diagnostic value is $43 \%$ and the negative diagnostic value is $93 \%$. Diagnosis of uterine fibroids the sensitivity of ultrasound is $67 \%$; specificity is $94 \%$; The positive diagnosis value is $60 \%$ and the negative diagnostic value is $95 \%$.

Keywords: Uterine chamber, histopathology, ultrasound

\section{I. ĐẶT VẤN ĐỀ}

Các bất thường buồng tử cung như: $u$ xơ, polype, u xơ dưới niêm mạc, vách ngăn, dính buồng, quá sản niêm mạc... gây ra rong kinh, rong huyết, ra máu bất thường đặc biệt gây vô sinh, sảy thai liên tiếp, thiếu máu do ra máu kéo dài. Các bất thường này ảnh hưởng rất nhiều đến kinh tế và cuộc sống của người bệnh. Việc phát hiện, chẩn đoán sớm các bệnh lý trên giúp thây thuốc lâm sàng ra quyết định kịp thời điều trị tích cực nhằm hạn chế tối đa các biến chứng, đảm bảo chất lượng cuộc sống cho bệnh nhân.

Ngày nay, đề chẩn đoán các bất thường trong buồng tử cung, ngoài biểu hiện của các triệu chứng lâm sàng, đã có một số phương pháp thăm dò hỗ trợ có tính chất quyết định như: siêu âm, chụp buồng tử cung có bơm thuốc cản quang [3], [4], [5]. 